\title{
Keanekaragaman Avertebrata Air Di Perairan Rawa Pulau Salah Nama Sungai Musi Bagian Hilir Sumatera Selatan
}

\author{
Mirna Dwirastina ${ }^{*}$ dan Agnes Puspita Sudarmo ${ }^{2}$ \\ *e-mail : mirna.rastina@gmail.com \\ ${ }^{1}$ Balai Riset Perikanan perairan Umum dan Penyuluhan Perikanan \\ ${ }^{2}$ Pascasarjana Prodi Manajemen Perikanan Universitas Terbuka
}

\begin{abstract}
Salah Nama Island is a swamp water that is affected by tides. Around the island there are several types of riparian vegetation from aquatic plants and human settlements. The island is surrounded by the Musi River Basin so that there are fishing activities, using several fishing gear, especially spears and nets. High biodiversity including fish, crustaceans, molluscs, reptiles that function to maintain environmental balance. Various types of aquatic biota found in the Musi River including aquatic plants and fish. The absence of information and research conducted on Salah Nama Island especially about invertebrate biota as an indicator of water, this became the basis for the idea of conducting research. This study aims to determine the composition, abundance and diversity of invertebrates in the waters of Salah Nama Island. The study was conducted in the waters of Salah Nama island in August, November 2016 and January 2017. Sampling locations were 5 stations. The research method uses porposive sampling method. Intake of invertebrates using a scoop so that the results of the scoop is put in plastic, given preservatives and taken to the laboratory to be identified. The identification results found there are 3 classes of invertebrates, namely Gastropods, Insecta and Malacostraca. The highest composition is the gastropod class. The abundance of aquatic invertebrates ranges from 99.08 to $1047.5 \mathrm{idv} / \mathrm{cm} 2$, the diversity index value ranges from $1<\mathrm{H}<3$, this value indicates the condition of the waters on Salah Nama Island is stable.
\end{abstract}

Keywords: Invertebrates, Composition, Abundance, Diversity, Musi River, Salah Nama Island

\begin{abstract}
ABSTRAK
Pulau Salah Nama adalah perairan rawa yang terkena pasang surut. Di sekitar pulau ditumbuhi beberapa jenis vegetasi riparian dari tanaman air, dan pemukiman penduduk. Pulau ini dikelilingi oleh DAS Musi sehingga terdapat kegiatan penangkapan, dengan menggunakan beberapa alat tangkap, terutama tombak dan jaring. Keanekaragaman hayati yang tinggi termasuk ikan, krustasea, moluska, reptil yang berfungsi menjaga keseimbangan lingkungan. Berbagai jenis biota perairan yang ditemukan di Sungai Musi termasuk tanaman air dan ikan. Belum adanya informasi dan penelitian yang dilakukan di Pulau Salah khusunya tentang biota invertebrata sebagai indikator perairan, hal ini menjadi dasar munculnya ide melakukan penelitian. Penelitian ini bertujuan untuk mengetahui komposisi, kelimpahan dan keanekaragaman invertebrata di perairan Pulau Salah Nama. Penelitian dilakukan di perairan Pulau Salah Nama pada Agustus, November 2016 dan Januari 2017. Lokasi pengambilan sampel adalah 5 stasiun. Metode penelitian menggunakan metode porposive sampling. Pengambilan invertebrata menggunakan serok sehingga hasil serok dimasukkan dalam plastik, diberi bahan pengawet dan dibawa ke laboratorium untuk diidentifikasi. Hasil identifikasi ditemukan ada 3 kelas invertebrata, yaitu Gastropoda, Insecta dan Malacostraca. Komposisi tertinggi adalah kelas gastropoda. Kelimpahan invertebrata air berkisar 99,08 hingga $1047,5 \mathrm{idv} / \mathrm{cm} 2$, nilai indeks keanekaragaman berkisar dari $1<\mathrm{H}<3$, nilai ini menunjukkan kondisi perairan di Pulau Salah Nama stabil.
\end{abstract}


Kata kunci: Invertebrata, Komposisi, Kelimpahan, Keanekaragaman, Sungai Musi, Pulau Salah Nama

\section{PENDAHULUAN}

Pemantauan kualitas perairan sungai-sungai umumnya dilakukan dengan menggunakan parameter fisik dan kimia. Tetapi ini pemantauan dengan menggunakan biota lebih diperhatikan, mengingat biota lebih tegas dalam mengekspresikan kerusakan sungai. Pengamatan dan pemeriksaan secara biologi merupakan cara yang paling baik dan cepat untuk mendeteksi adanya kerusakan pada kehidupan akuatik (Plafkin, et al..1985).

Penelitian biota air dengan avertebrta air memiliki banyak manfaat untuk mengetahui adanya perubahan lingkungan akibat kegiatan manusia (antropogenik). Avertebrata air merupakan salah satu indikator kesehatan lingkungan akuatik. Hewan ini hidup di bawah-bawah tanaman ataupun menempel pada tanaman dengan pola migrasi terbatas dan cenderung menetap (Chessman, 1995; Plafkin, dkk., 1985).

Pulau Salah Nama merupakan suatu Pulau Yang ada di Kelurahan
Mariana Ilir kabupaten Banyuasin 1 sungai Musi Bagian Hilir Sumatera Selatan. Di Pulau Ini masih banyak ditemukan Tanaman baik di Pinggiran Pulau Salah Nama. Pulau ini merupakan daerah perairan Rawa yang dipengaruhi pasang surut. Pulau Salah Nama terletak di tengah sungai Musi yang tutupan lahanya sebagian kecil berupa hutan Pedado, dan dibagian yang tidak dimasukin air pasang berupa sawah penduduk. Penelitian ini bertujuan untuk mengetahui kekayaan dan keanekaragaman avertebrata air di Pulau Salah Nama Sungai Musi Bagian Hilir Sumatera Selatan.

\section{BAHAN DAN METODE}

Penelitian dilaksanakan mulai bulan Agustus 2016, November 2016 dan Januari 2017 di Pulau Salah Nama Sungai Musi Bagian Hilir Sumatera Selatan (Gambar 1).

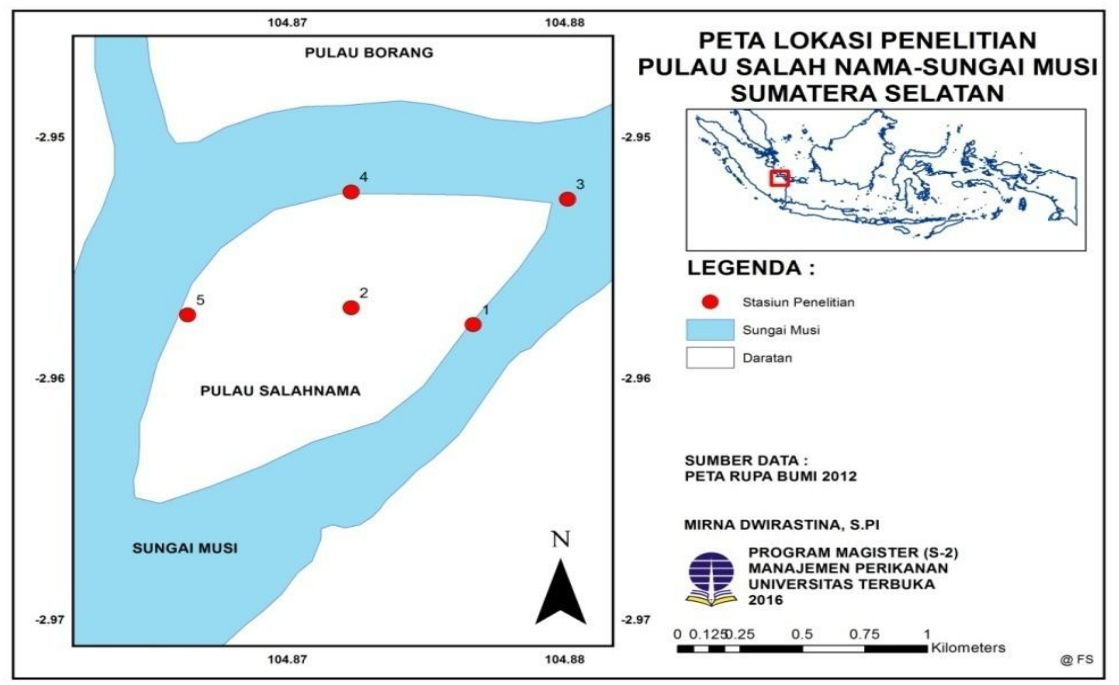

Gambar 1. Lokasi Pulau Salah Nama Sumatera Selatan

Avertebrata air diambil menggunakan alat serok yang terbuat dari jaring berukuran mata jaring $1 \mathrm{~mm}$. Bagian perairan yang dipilih antara lain 
dibawah pohon yang roboh, dibawah tumbuhan yang terendam air atau pada kayu-kayu mati. Hasil serok dimasukkan ke dalam kantong plastik, diberi pengawet alkohol teknis dan dibawa kelaboratorium untuk diidentifikasi di Laboratorium Penguji Balai Penelitian Perikanan Perairan Umum Palembang. Identifikasi avertebrata air merujuk kunci identifikasi Borror, et al..(1996), Bugguidenet (2007), Suin (1997), Lilies (1992) dan Merrit, et al.. (1996).

Avertebrata dihitung merujuk Odum

(1971) sebagai berikut :

$$
\mathrm{K}=\frac{10000 \times \mathrm{a}}{\mathrm{B} \times \mathrm{n}}
$$

Dimana :

$\mathrm{K}=$ Kepadatan/kelimpahan avertebrata air (Individu $/ \mathrm{m}^{2}$ )

$\mathrm{a}=$ Jumlah individu Avertebrta jenis ke1 yang diperoleh

$\mathrm{B}=$ Luas bukaan/mulut jaring avertebrata yang digunakan $\left(\mathrm{cm}^{2}\right)$ $10000=$ nilai konstanta $\mathrm{cm}^{2}$ menjadi $\mathrm{m}^{2}$

$\mathrm{n}=$ Jumlah ulangan pengambilan (cuplikan)

\section{$\frac{\text { NXAtxVt }}{A C x V S X A S}$}

Indeks keanekaragaman dihitung dengan rumus (Shannon dan Wiever, 1949 diacu oleh Ludwig and Reynolds, 1988):

$$
\mathbf{H}^{\prime}=-\Sigma_{i=\mathbf{1}}^{z} \text { pi Lmpi }
$$

Keterangan:

$\mathrm{H}^{\prime}$ = Indeks keanekaragaman jenis

$\mathrm{S}$ = Banyaknya jenis

$$
\begin{aligned}
& p i=\mathrm{ni} / \mathrm{N} \\
& \mathrm{ni}=\text { Jumlah individu jenis ke-i } \\
& \mathrm{N}=\text { Jumlah total individu }
\end{aligned}
$$

Indeks dominasi perifiton dihitung dengan rumus (Ludwig and Reynolds, 1988):

Keterangan:

$$
\mathrm{C}=\sum_{i=1}^{s}(p i)^{2}
$$

$\mathrm{D}=$ Indeks dominasi

$\mathrm{pi}=\mathrm{ni} / \mathrm{N}$

$\mathrm{ni}=$ jumlah individu dari spesies ke- $i$

$\mathrm{N}=$ Jumlah total individu $\mathrm{S}=$ Jumlah spesies.

\section{HASIL DAN PEMBAHASAN}

Berdasarkan hasil identifikasi maka ditemukan ada 3 kelas avertebrata air yang ditemukan yaitu Gastropoda, Insekta dan Malacostraca. Pada Gambar 2 terlihat bahwa kelas Gastropoda pada bulan Januari mengalami kenaikan dibanding bulan lainya. Januari merupakan musim pasang besar yang terjadi di perairan rawa Pulau Salah Nama Sumatera Selatan. Pada bulan Januari mengalami pasang tertinggi yang terjadi di Sungai Musi atau dengan kata lain banjir besar.

Genera pada kelas Gastropoda yang sering ditemukan adalah Pomacea $\mathrm{sp}$. Indoplanorbis sp, Bellamya $\mathrm{sp}$, dan Digoniostoma sp. Kelas Insekta terdiri dari ordo Hemiptera (Ctenipocorosis sp), Ephemeptera (Baetis sp), Diptera (Chironomus sp, Ceratoponogonidae), dan Colepotera (Cybister), Kelas Malacostraca (Parathelphusa sp). 


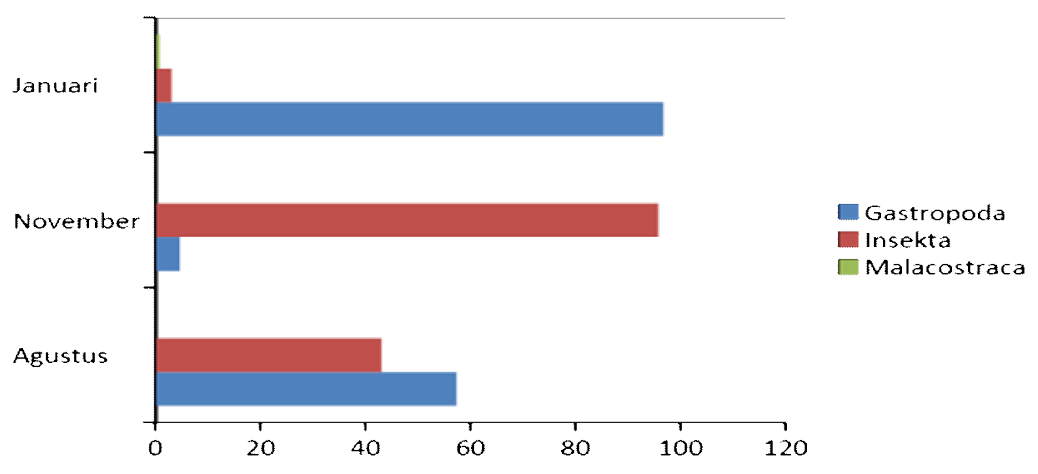

Gambar 2. Persentase komposisi avertebrata air di Pulau Salah Nama Agustus 2016 s/d Januari 2017

Gastropoda adalah hewan yang bertubuh lunak, berjalan dengan perut yang dalam hal ini disebut kaki. Gerakan Gastropoda disebabkan oleh kontraksikontraksi otot seperti gelombang, dimulai dari belakang menjalar ke depan. Pada waktu bergerak, kaki bagian depan memiliki kelenjar untuk menghasilkan lendir yang berfungsi untuk mempermudah berjalan, sehingga jalannya meninggalkan bekas. Hewan ini dapat bergerak secara mengagumkan, yaitu memanjat ke pohon tinggi atau memanjat ke bagian pisau cukur tanpa teriris. Menurut Winarno., et al..(2000) keberadaan Mollusca termasuk kelas Gasropoda sangat dipengaruhi ketinggian tempat dari permukaan laut (altitude). Familia ini umumnya melimpah pada ketinggian rendah (Hubbard dan Peters, 1984). Pada musim hujan, dimana masukan bahan organik meningkat dan luasan badan air bertambah, antara lain dengan terbentuknya dataran banjir, maka sebagian besar anggotanya melakukan reproduksi, sehingga tingkat kemelimpahannya sering kali bertambah. Mollusca umumnya hidup sebagai meiobentos di dalam sedimen, meskipun ada pula yang hidup di permukaan batuan atau menempel pada makrofita akuatik.

Kelas Insekta menempati urutan kedua setelah Gastropoda. Menurut Voshell (2003), salah satu hal yang menakjubkan dari serangga air adalah beragamnya habitat mereka hidup. Tidak ada suatu badan perairan yang kondisinya terlalu kecil, terlalu besar, terlampau dingin atau panas, keruh atau berlumpur, dengan kadar oksigen terlampau rendah, arus yang terlalu deras, atau tempat yang terlalu banyak polusi untuk beberapa jenis serangga air untuk dapat hidup di sana. Menurut Winarno., et al..(2000) Insecta umumnya mendominasi kehidupan bentos di perairan yang cenderung masih perawan/asli dan terletak di dataran tinggi. Golongan ini lebih banyak hidup di permukaan bebatuan (makrobentos) dari pada di dalam sedimen (meiobentos). Menurut Hubbard dan Peters (1984), pada ketinggian rendah, yakni di bawah $300 \mathrm{~m}$ dpl keanekaragaman dan kekayaan jenisnya mulai berkurang. Menurut Voshell (2003), salah satu hal yang menakjubkan dari serangga air adalah beragamnya habitat mereka hidup. Serangga air merupakan salah satu sumber makanan bagi ikan-ikan di perairan umum. Kelimpahan dan aktivitas reproduksi serangga di daerah tropik sangat dipengaruhi oleh musim, karena musim berpengaruh kepada ketersediaan bahan makanan dan kemampuan hidup serangga yang secara langsung dapat mempengaruhi kelimpahan.

Pada pengamatan bulan Agustus 2016 termasuk kategori bulan kemarau karena sebagian lokasi ada yang kering dan air sangat surut sehingga 
memungkinkan jenis gastropoda meningkat dan menempel di substrat daun-daun tanaman air. Pada bulan November air mulai naik sehingga peralihan musim sehingga air mulai naik sehingga terjadi fluktuasi air yang menyebabkan serangga air mulai banyak untuk berkembang. Sedangkan bulan Januari 2017 musim hujan sehingga areal
Pulau Salah Nama hampir terendam air dari sungai musi dan ketinggian air sangat tinggi sehingga semua lokasi penelitian terendam oleh air. Dengan demikian daerah Pulau Salah Nama terkena pasang besar dan banyak Gastropoda yang menempel di substrat tanaman untuk berahan hidup.

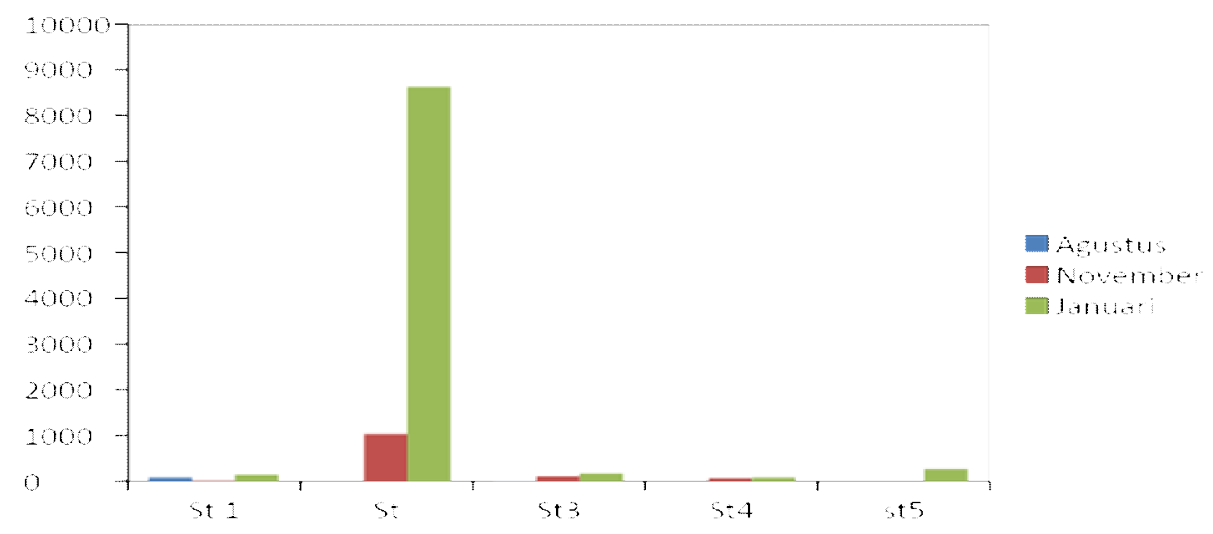

Gambar 3. Kelimpahan Avertebrata Air di Pulau Salah Nama Sumatera Selatan

Berdasarkan perhitungan maka kelimpahan avertebrata bulan Agustus (Gambar 14 a) tertinggi pada stasiun 1 yaitu $99,08 \mathrm{idv} / \mathrm{cm}^{2}$, stasiun 1 mewakili daerah pemukiman. Kelas Gastropoda merupakan kelas yang paling banyak ditemukan, hal ini karena pada stasiun tersebut ditemukan banyak banyak tanaman air sehingga beberapa jenis dari kelas Gastropoda menempel pada tanaman air tersebut. Pada bulan Agustus ditemukan sedikit sekali avertebrata air hal ini dikarenakan pada saat pengambilan sampel bulan Agustus masih bulan kemarau sehingga air cenderung surut bahkan beberapa stasiun mengalami kekeringan. Pada bulan November kelimpahan berkisar 85$1047,4 \mathrm{idv} / \mathrm{cm}^{2}$ (Gambar 14b), hal ini dikarena bulan ini sudah termasuk musim hujan dan air mulai banyak sehingga hampir semua stasiun air mengalami kenaikan. Sedangkan bulan Januari kelimpahan berkisar 99,08 $-86,34$ $\mathrm{idv} / \mathrm{cm}^{2}$ (Gambar $\left.14 \mathrm{c}\right)$. Bulan November air mulai tinggi sedangkan bulan Januari air sangat tinggi sehingga hampir seluruh stasiun terendam air bahkan Pulau Salah Nama terendam semua oleh Sungai Musi.

Nilai kelimpahan tertinggi terjadi pada saat musim air naik atau musim penghujan terutama kelas gastropoda, hal ini dikarenakan pada musim hujan permukaan air naik sehingga avertebrata kelas gastropoda air bertahan hidup dengan cara menempel atau mengitari tumbuhan air . Kelas Gastropoda yang banyak ditemukan yaitu gastropoda jenis Digoniostom $s p$ serta selain kelas gastropoda diiringi juga kelas insekta jenis Ctenepocorosis sp. Gastropoda akan bersifat menggali atau menempel kepada akar, batang atau daun tanaman air .

Selama tanaman sekitar masih banyak dan ada serta lingkungan yang mendukung maka gastropoda masih akan ditemukan, tetapi apabila tanaman sudah tidak ada lagi maka akan berkurang juga gastropoda tersebut. Tanaman air sangat berpengaruh terhadap keberadaan gastropoda tersebut terutama untuk kelangsungan hidup dan lain-lain. Dengan demikian berdasarkan penelitian 
ini tanaman air berpengaruh terhadap

keberadaan gastropoda tersebut.
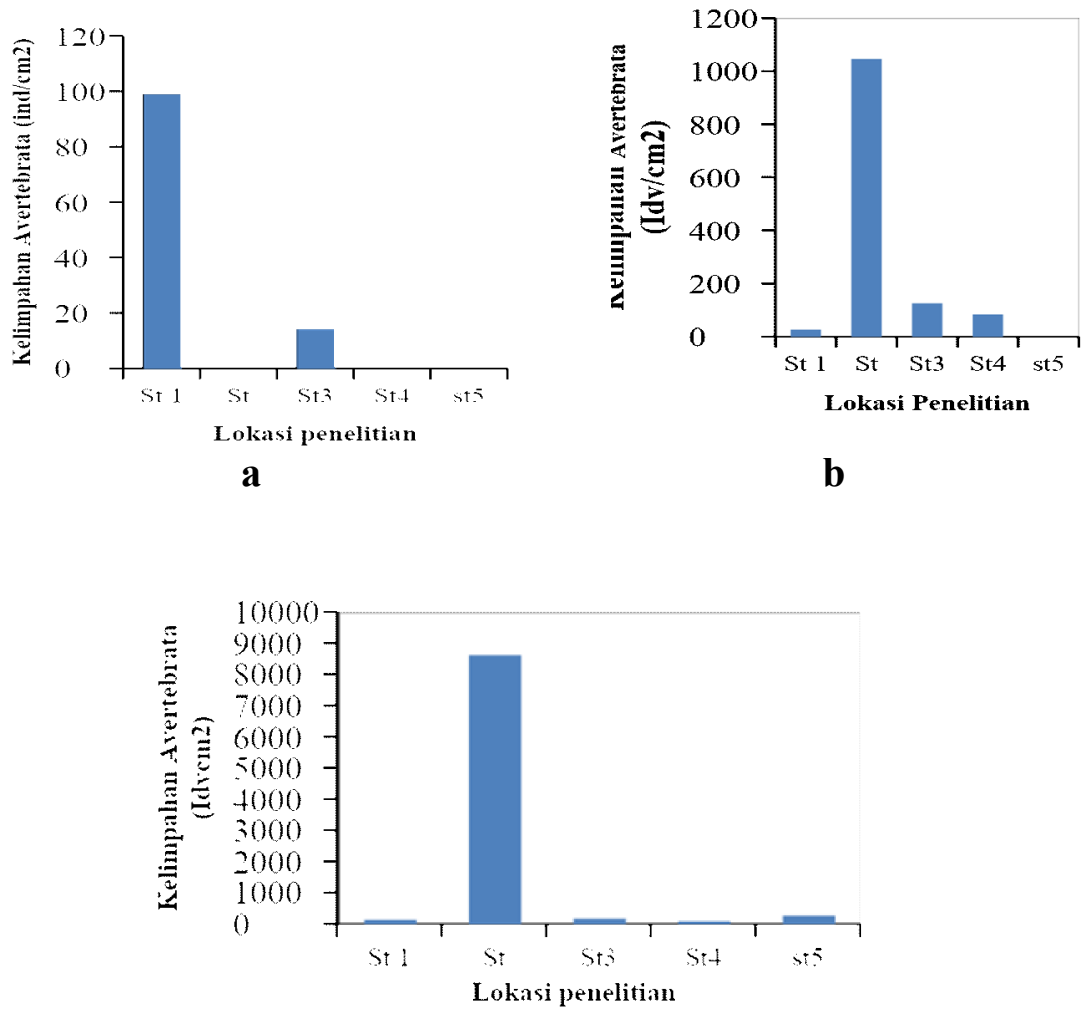

Gambar 4. Kelimpahan Avertebrata air di Pulau Salah Nama Agustus, November 2016 dan Januari 2017

Nilai indeks keanekaragaman avertebrata air berkisar 0-2, keanekaragaman ini termasuk dalam kategori sedang atau masih kategori stabil (Gambar 15). Berdasarkan hasil perhitungan yang didapat maka avertebrata yang didapat tidak terlalu banyak tetapi masih termasuk stabil, hal ini karena masih ditemukannya jenis avertebrata serta meskipun tidak ada jenis yang mendominasi di perairan tersebut. Apabila ditinjau dari jenis-jenis tanaman air yang dihasilkan masih kategori bagus dan beragam, sedangkan avertebrata yang dihasilkan tidak beragam hanya jenis tertentu saja tetapi kelimpahan cukup stabil. Hal ini dikarenakan faktor pasang surut yang sudah berpengaruh di daerah ini, serta adanya pengaruh terhadap aktivitas nelayan yang menangkap ikan tidak ramah lingkungan yaitu menggunakan racun /strum Secara tidak langsung mempengaruhi keseimbangan, keragaman biota-bioa air yang ada di daerah tersebut. Yuniarti (2012) dalam Nurjanah, dkk (2013) menambahkan, tinggi rendahnya tingkat keanekaragaman dipengaruhi oleh kesuburan habitat yang dapat mendukung kehidupan setiap spesies yang menempati tempat tersebut. 

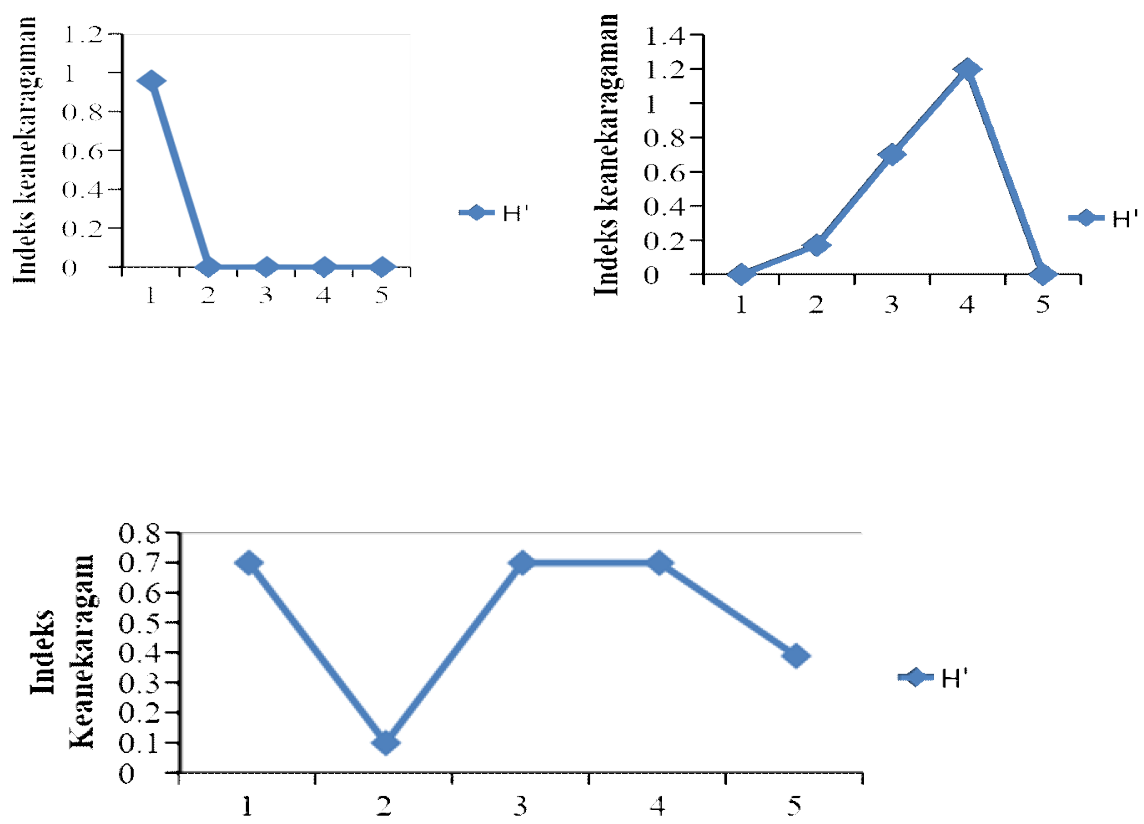

Gambar 5. Nilai Indeks Keanekaragaman avertebrata di Pulau Salah Nama Agustus, November 2016 dan Januari 2017

\section{KESIMPULAN}

Berdasarkan penelitian yang dilakukan maka dapat ditarik suatu kesimpulan adalah sebagai berikut:

1. Hasil identifikasi avertebrata ditemukan 3 kelas yaitu Gastropoda, Insekta dan Malacostraca.

2. Kelimpahan avertebrata air berkisar 99,08-1047,5 idv/ $\mathrm{cm}^{2}$,

3. Nilai indeks keanekaragaman berkisar $1<\mathrm{H}<3$, nilai ini menandakan kondisii perairan masih kategori sedang dan stabil.

\section{DAFTAR PUSTAKA}

Borror, Donald J. Charles A. Triplehorn, Norman F. Johnson. (1996). Pengenalan Pelajaran Serangga. Diterjemahkan oleh.Partosoedjono. Edisi keenam. Yogyakarta : Penerbit Gadjah Mada University.

Chessman, B.C. (1995). Rapid assessment of river using macroinvertebrates: A procedure based on habitat specific sampling, family level identification and a biotic index. Aus. J. Ecol. 20: 122-129

Hubbard W.D. dan W.L. Peters. (1984). Ephemeroptera of Sri Langka: an Introduction to Their Ecology and Biogeography. Dalam c.H. Fernando (ed.) Ecology and Biogeography in Sri Langka. The Hague: W. Junk Publishers

Ludwig, JA, Reynold, JF. (1988). Statistical Ecology. A. Primer on Method on Competing: Jhon Willey and Sons

Merritt, R. W. and Cummins, K. W. (1996). An Introction to the Aquatic Insect Of North America. Dubuque : Kendall / Hunt Publishing Company.

Nurjanah, A.M. Jacoeb, R.G. Fetrisia. (2013). Komposisi kimia kerang 
pisau (Solen spp.) dari pantai

Kejawanan, Cirebon, Jawa

Barat. Jurnal Pengolahan Hasil

Perikanan Indonesia, 16(1):22-

32.

Odum EP. (1971). Fundamental of Ecology. Ed ke-3.Philadelphia: W.B Saunders Co.

Plafkin, J.L., M.T. Barbour, K.D. Porter,

S.K. Gross, and R.M. Hughes. (1985).

Rapid Bioassessment Protocols For Use in Streams and Rivers: Benthic Macroinvertebrates and Fish. Washington D.C.: USEPA, Assessment and Watershed Protection Division

Suin. (1997). Ekologi Hewan Tanah. Jakarta : Bumi Aksara.

Voshell, Reese J., (2003). Sustaining America's Aquatic BiodiversityAquatic Insect Biodiversity and Conservation. Department of Entomology. Virginia Tech Sumber: http://www.ext.vt.edu/pubs/fishe ries/420-531/420-531.html\#L3 diunduh tgl. 12 Maret 2008.

Winarno, K., O.P.Astirin., A.D. Setyawan. (2000). Pemantauan Kualitas Peraiaran Rawa Jabung Berdasarkan Keanekaragaman dan Kekayaan Komunitas Bentos. BIOSMART Vo. 2. No.1. 